\title{
Program uptake of a parent-tailored telephone smoking cessation counselling: An examination of recruitment approaches
}

\author{
Tessa Scheffers-van Schayck ${ }^{1,2}$, David W. Wetter ${ }^{3}$, Roy Otten ${ }^{4,5,6}$, Rutger C. M. E. Engels ${ }^{7}$, Marloes Kleinjan ${ }^{2,8}$
}

\begin{abstract}
INTRODUction Recently, a Dutch proactive parent-tailored telephone smoking cessation counselling program, Smoke-free Parents (SFP), was demonstrated to be effective in helping parents to quit smoking. This study aimed to examine the program's uptake and the costs of two recruitment approaches (i.e. healthcare vs mass media) for SFP. In addition, parent's barriers to participating in SFP and the characteristics of participating parents were assessed.

METHODS As part of an effectiveness-implementation hybrid trial, 402 smoking parents were recruited via healthcare settings and mass media for an informal, proactive, and free phone call with a smoking cessation counsellor about SFP (the Netherlands, September 2016 - September 2018). Parents were asked whether they wanted to participate in SFP. If parents refused, reasons for decline and additional information (e.g. educational level) were collected.

RESULTS Results revealed that $26.4 \%$ of the recruited parents participated in SFP. Although the program uptake of parents recruited via mass media was slightly, but not significantly, higher than via healthcare $(27.3 \%$ vs $26.8 \%, p=0.92)$, the healthcare approach resulted in lower costs per participant (€99.62 vs €205.72). Smoking cessation counsellors were unable to reach almost one-third $(32.7 \%)$ of the parents after they had agreed to be called about SFP.

CONCLUSIONS The present study showed that more than a quarter of all recruited parents participated in SFP and that the mass media approach and healthcare approach can be used to recruit parents for SFP. To increase the number of parents participating in SFP, it is important to overcome the identified barriers that prevent parents from participating.
\end{abstract}

AFFILIATION

1 Epidemiology and Research Support, Trimbos Institute, Netherlands Institute of Mental Health and Addiction, Utrecht, the Netherlands

2 Department of Interdisciplinary Social Sciences, Utrecht University, Utrecht, the Netherlands

3 Center for Health Outcomes and Population Equity, Huntsman Cancer Institute, the University of Utah, Salt Lake City, United States 4 Research and Development, Pluryn, Nijmegen, the Netherlands 5 Department of Psychology, ASU REACH Institute, Arizona State University, Tempe, United States 6 Developmental Psychopathology, Radboud University, Nijmegen, the Netherlands

7 Executive Board, Erasmus University Rotterdam, Rotterdam, the Netherlands

8 Youth, Trimbos Institute, Netherlands Institute of Mental Health and Addiction, Utrecht, the Netherlands

CORRESPONDENCE TO

Tessa Scheffers-van Schayck. Epidemiology and Research Support, Trimbos Institute, Netherlands Institute of Mental Health and Addiction, Utrecht University, P.0. Box 735, 3500 AS, Utrecht, the Netherlands. E-mail: tscheffers@trimbos.nl

KEYWORDS

smoking cessation, parents, barriers, recruitment, telephone counselling, program uptake

Received: 14 September 2020

Revised: 22 January 2021

Accepted: 2 February 2021 


\section{INTRODUCTION}

Children's exposure to secondhand smoke (SHS) occurs predominantly at home, with parents and other relatives who smoke ${ }^{1}$, and has adverse consequences for children's health, including increased risk of asthma ${ }^{2,3}$. In addition, thirdhand smoke (THS), the residual tobacco smoke pollutants that remain in dust and on surfaces, may also have adverse health consequences ${ }^{4}$. Fortunately, many parents want to quit smoking ${ }^{5}$, providing a key opportunity to increase the number of parents that quit and improve their health and to decrease the number of children exposed to SHS and THS.

Recently, a proactive telephone-based smoking cessation counselling program tailored to parents, called Smoke-free Parents (SFP), was examined in the Netherlands ${ }^{6}$. Parents were proactively contacted and offered services by a smoking cessation counsellor. In this randomized controlled trial (RCT), smoking parents $(\mathrm{n}=512)$ received telephone counselling or a self-help brochure (control condition). Results revealed that 12 months after the intervention began, $34.0 \%$ of the parents in the intervention condition reported 7-day point prevalence abstinence versus $18.0 \%$ of the parents in the control condition (OR=2.81; 95\% CI: 1.76 4.49). Based on these findings, the program has the potential to help parents quit smoking and protect their children from SHS and THS exposure at home ${ }^{6}$.

The impact of an intervention does not depend solely on the efficacy of the intervention but also on the extent to which the intervention is accepted and utilized by its intended targets ${ }^{7}$. In other words, once parents are recruited for a smoking cessation intervention, it is crucial that they actually start the intervention, i.e. program uptake. With respect to SFP, it is currently unknown to what extent parents are likely to start the telephone counselling program after being recruited via different approaches, e.g. healthcare settings, and whether the program uptake differs between recruitment approaches. More information about the program uptake of SFP via different recruitment approaches is needed for a successful implementation of SFP on a national scale. For implementation purposes, it is also important to gain information about: 1) the relative costs of the recruitment approaches, i.e. cost per participant, CPP; 2 ) barriers that prevent parents from participating in SFP; and 3) whether participating parents have different characteristics from non-participating parents. The present study aims to address these issues by examining the program uptake of parents in SFP following two recruitment approaches via mass media and healthcare settings. The mass media approach was chosen because of its ubiquitous use by population-level cessation programs, e.g. quitlines. Moreover, a broader group of smoking parents can be recruited via the mass media approach compared to the healthcare approach, since not every parent visits healthcare professionals in hospitals or youth healthcare centers. Healthcare settings were chosen because parents are receptive to cessation interventions in these settings and these settings could serve as 'teachable moments' ${ }^{8-10}$.

Based on prior research on recruiting parents for smoking cessation interventions via healthcare settings ${ }^{8,9,11,12}$, we expected that the program uptake would be higher for the healthcare approach than for the mass media approach. No explicit hypothesis was formulated beforehand with respect to the two approaches' recruitment costs. Characteristics of the participating parents, including age, gender, educational level, and average number of cigarettes smoked per day, were examined. It was hypothesized that participating parents had higher education levels and smoked fewer cigarettes per day on average than parents who did not participate in $\mathrm{SFP}^{13,14}$

\section{METHODS}

\section{Study design}

This study was part of a large effectivenessimplementation hybrid trial ${ }^{15,16}$ of the Dutch counselling program SFP. More information on the study design can be found elsewhere ${ }^{17,18}$. This study was registered in the Netherlands Trial Register (NTR6092) and approved by the ethics committee of the Trimbos Institute (201607_52-1606).

\section{Recruitment}

The two recruitment approaches, mass media approach and healthcare approach, are described briefly below and more extensively elsewhere ${ }^{17,18}$.

\section{Mass media approach}

The mass media approach included two recruitment 
channels: primary schools and online mass media.

\section{Primary schools}

Between September and November 2016, 619 primary schools throughout the Netherlands were randomly selected and asked to distribute invitation letters to parents of children aged 4-12 years for registration for the RCT. In total, 101 (16.3\%) schools agreed to do so. Most schools that did not participate indicated that they were too busy, that they do not see it as their task to promote smoking cessation or that their standard answer to questions on possible research involvement is no. Because fewer parents registered for the study than expected, the same schools were asked to bring the study to parents' attention a second time. Because the aim was to examine the recruitment of parents for SFP under real-world conditions as much as possible, the content of the invitation letters was changed compared to the first invitation. Instead of inviting parents to participate in the study, parents received information about SFP and were invited to register for a free proactive phone call with a smoking cessation counsellor, during which parents were invited to participate in the RCT (see Procedure section for more information). In total, $77.0 \%$ of the 101 primary schools agreed to distribute the letters a second time.

\section{Online mass media}

Parents were recruited through two smoking cessation websites, one of which can be found on every Dutch cigarette pack, where parents could find information about SFP and could register for a free proactive phone call with a smoking cessation counsellor. In addition, multiple paid social media advertisements aimed at motivating parents to quit smoking and register for a free call about SFP were deployed between September 2017 and January 2018. Because fewer parents registered than expected, a specialized advertising agency was hired to develop five advertisements targeting smoking parents. These advertisements were deployed between January 2018 and May 2018 (Figure 1, in Dutch with English translation). In total, 17807 people were reached with at least one of the five advertisements. The total number of clicks on the five advertisements was 1754 and the total impressions was 66156, which leads to a click-through rate (i.e. number of clicks on the advertisements divided by the impressions of the advertisements) of $2.6 \%$.

\section{Healthcare approach}

The healthcare approach included two different groups of healthcare professionals: general healthcare professionals and youth healthcare professionals. In the Netherlands, youth healthcare provides preventive healthcare to all children aged 0-17 years. Around $95 \%$ of Dutch parents with children aged $0-4$ years reported having visited maternity centres ${ }^{19}$. Youth healthcare professionals working at these centers participated in this study.

Several meetings were organized with a group of representatives of youth healthcare professionals and general healthcare professionals (hereinafter healthcare professionals) to develop the SFP referral tool and to ask them to promote SFP among their colleagues. Healthcare professionals interested in using the SFP referral tool could register for the study on the website. After registration, healthcare professionals received a phone call from the research team, during which they were given further information and could choose to withdraw or confirm their registration.

Between December 2016 and September 2018, healthcare professionals could refer parents to SFP by asking them whether they were interested in receiving a free proactive phone call in which information was provided on the SFP program by a smoking cessation counsellor. Parents who agreed were registered by phone, fax or online. To assist healthcare professionals with referring parents to SFP, a toolkit was developed containing an SFP poster, a small information card for parents, and an information card for healthcare professionals on the referral tool.

\section{Procedure}

After parents were recruited through the mass media approach or healthcare approach, three smoking cessation counsellors of SineFuma (a Dutch certified quitline) attempted to reach parents up to five times via telephone, text messages, e-mail and/or a messaging app at different moments during the day. Following a script, the counsellors screened parents for the RCT inclusion criteria: 1) being recruited via the mass media approach or healthcare approach and 
Trimbos-instituut

Sponsored $\cdot$ (a)

Roken vergroot de kans dat uw kinderen astma en andere longproblemen ontwikkelen. Stop daarom met roken! Vraag een vrijblijvend en gratis telefoongesprek aan met een stoppenmet-roken coach en bespreek hoe $u$ het beste kunt stoppen met roken!

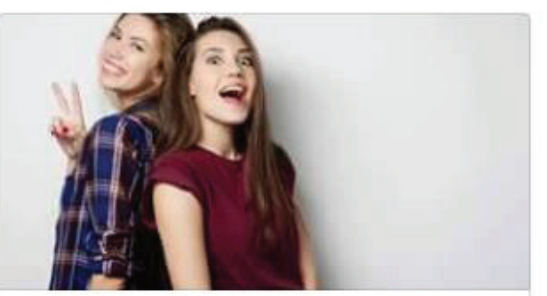

Programma Rookvrije Ouders Bekijk de voordelen van dit programma! Sign Up www.rokeninfo.nl

(1) $\%$ You and 40 ot A

Trimbos-instituut Sponsored · a

"Had ik maar eerder geweten dat mijn rookgedrag ook ongezond is voor mijn kinderen, dan was ik al veel eerder gestopt met roken. Mijn advies aan andere ouders: stop ook met roken! Vraag een vrijblijvend en gratis telefoongesprek aan met een stoppen-metroken coach en bespreek hoe $u$ het beste kunt stoppen met roken!"

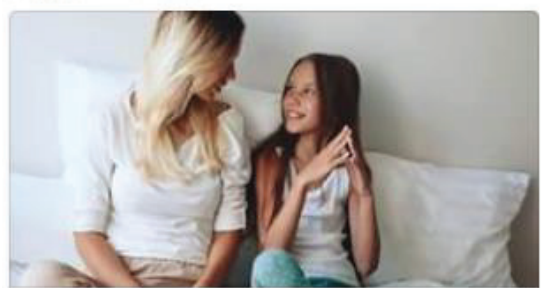

\section{Programma Rookvrije}

\section{Ouders}

www.rokeninfo.n

(b) : You and 50
Learn More

$\mathrm{D}^{\text {'s } \quad 13 \text { comments }}$

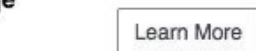

Trimbos-instituut

Sponsored : a

Bijna geen enkele rokende ouder wil dat zijn of haar kind later ook gaat roken. U ook niet? Stop dan zelf met roken! Vraag een vrijblijvend en t-roken coach en bespreek hoe $u$ het beste

\section{Programma Rookvrije}

Ouders

$8 \geqslant 22$

$\mathrm{B}$
Trimbos-instituut
Sponsored $\cdot$ in

Een kwart van de zware rokers overlijdt voor hun $65 \mathrm{e}$. Wilt u uw toekomstige kleinkinderen zien opgroeien? Stop dan nu met roken! Vraag een vrijblijvend en gratis telefoongesprek aan met een stoppen-met-roken coach en bespreek hoe $\mathrm{u}$ het beste kunt stoppen met roken!

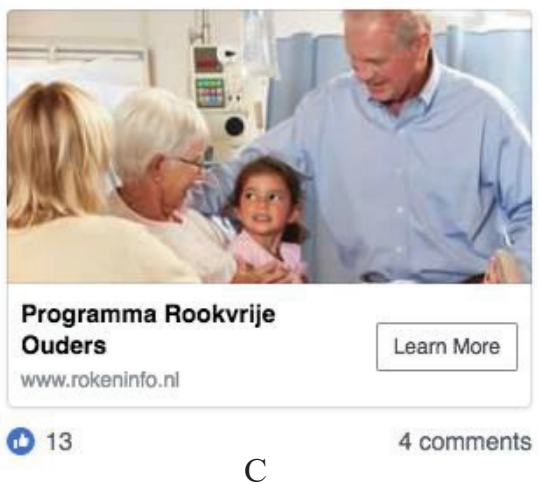

A: Smoking increases the chance for your children to develop asthma and other respiratory illnesses. So quit smoking! Ask for an informal and free phone call with a smoking cessation counselor to discuss how you can quit smoking best!

B: Almost no parent wants to see their children start smoking when they are older, don't you? Quit smoking! Ask for an informal and free phone call with a smoking cessation counselor to discuss how you can quit smoking best!

C: About $25 \%$ of heavy smokers die before their 65 th birthday. Would you like to see your grandchildren grow up? Quit smoking now! Ask for an informal and free phone call with a smoking cessation counselor to discuss how you can quit smoking best!

D: I wish I had known before that my smoking behavior has severe health consequences for my children, because then I would have quit smoking a lot sooner. My advice to other parents: quit smoking! Ask for an informal and free phone call with a smoking cessation counselor to discuss how you can quit smoking best!

E: Smoking increases the chance for your children to develop asthma and other respiratory illnesses. So quit smoking! Ask for an informal and free phone call with a smoking cessation counselor to discuss how you can quit smoking best! 
intending to quit smoking currently or in the future; 2 ) having children aged $0-18$ years; and 3 ) being at least weekly smokers. Eligible parents were informed about the RCT and about possible costs for the telephone counselling. When this study was conducted, most health insurance agencies reimbursed the costs for smoking cessation support, but the amount of reimbursement varied by health insurance type ${ }^{20}$. If parents agreed to participate in the RCT, the research team sent a registration form to parents to confirm their registration. Telephone counselling outside the RCT was offered to parents who declined participation or who did not fulfil the inclusion criteria. If parents did not wish to participate in the RCT or to receive telephone counselling outside it, they were asked to note a reason for declining. Data were collected on parents' gender, educational level, age, and average number of cigarettes smoked per day. The platform program Caspio (2018) was used to exchange data between SineFuma and the research team.

\section{Measures and statistical analyses}

The data were analyzed using Excel, SPSS (version 25.0), and R.

\section{Program uptake}

Program uptake was operationalized as the number of parents recruited via the recruitment approach divided by the number of parents that participated in $\mathrm{SFP}$, i.e. those who were randomized in the RCT plus those who received telephone counselling outside the RCT.

\section{Recruitment costs and CPP}

The recruitment costs for the mass media approach included: 1) the dissemination of letters to the schools; 2 ) the development and hosting of the study website for the schools; 3 ) the advertisements on social media; and 4) adding information about SFP to the national smoking cessation website. The recruitment costs for the healthcare approach included: 1) the development of materials for healthcare professionals; 2 ) the dissemination of materials to healthcare professionals; and 3 ) the recruitment of healthcare professionals at conferences (promotion costs). Personnel costs (e.g. costs of the research team's time investment) were not collected. To calculate the CPP for both recruitment approaches, the costs for each approach were divided by the number of parents that participated in SFP.

\section{Parents' barriers to participation in SFP}

During the informal phone call with the smoking cessation counsellors, parents were asked whether they wanted to participate in the RCT or receive SFP outside the study context (see Procedure section for more information). In case parents did not wish to participate in the RCT or to receive SFP outside the study context, the counsellors asked parents to give a reason for declining during the same phone call. The classification of these reasons included two stages. First, two members of the research team independently classified the first 75 reasons into categories (inductive coding) and searched for different themes between the categories. After reaching consensus about the categories and themes, the two researchers independently categorized the remaining 145 reasons. At the end of the first stage, 31 categories were constructed. In the second stage, these were combined into two main categories in discussion with a third researcher. The first category 'reasons for declining' included seven subcategories: 1) too expensive; 2) had already quit smoking; 3 ) did not want to quit smoking; 4) did not want to receive cessation assistance; 5 ) wanted to receive other cessation assistance; 6) had already found other cessation assistance; and 7) other. The second category 'other reasons for not participating after referral' included two subcategories: 1) unable to reach, identified by the research team when the smoking cessation counsellors were either unable to reach parents at all or unable to reach parents after they had been able to reach parents once; and 2) did not fulfil the inclusion criteria for participating in the RCT, e.g. being a parent/caretaker of a child aged 0-18 years ${ }^{18}$. A two proportion z-test was performed in $\mathrm{R}$ to test whether the parents' barriers were significantly more often found for the mass media approach or healthcare approach.

\section{Characteristics of parents who participated in SFP versus those who did not}

The smoking cessation counsellors asked parents several demographic and smoking-related characteristics, including gender, age, educational level (low/medium/high) ${ }^{21}$, and average number of cigarettes smoked per day. Parents who did not 
meet the inclusion criteria, or who were unable to reach were excluded from the analyses on the characteristics. In total, 257 parents were included in the analyses. However, due to missing values, the number of parents varied for each characteristic.

\section{RESULTS}

\section{Program uptake and recruitment costs}

The flow of parents through the study for the mass media approach and healthcare approach is depicted in Figures 2 and 3. Overall, 402 parents were recruited, of whom 106 (26.4\%) participated in SFP. The program uptake via the mass media approach $(n=39 ; 27.3 \%)$ and via the healthcare approach $(n=67 ; 26.8 \%)$ did not significantly differ $(p=0.92)$. More specifically, the program uptake via primary schools was $46.4 \%$ (number of parents that were recruited via primary schools: 28 ; number of parents that participated in SFP: 13). For online mass media, the program uptake was $22.6 \%$ (number of parents that were recruited via online mass media: 115; number of parents that participated in SFP: 26).

Figure 2. Flowchart mass media approach (The Netherlands, 2016-2018)

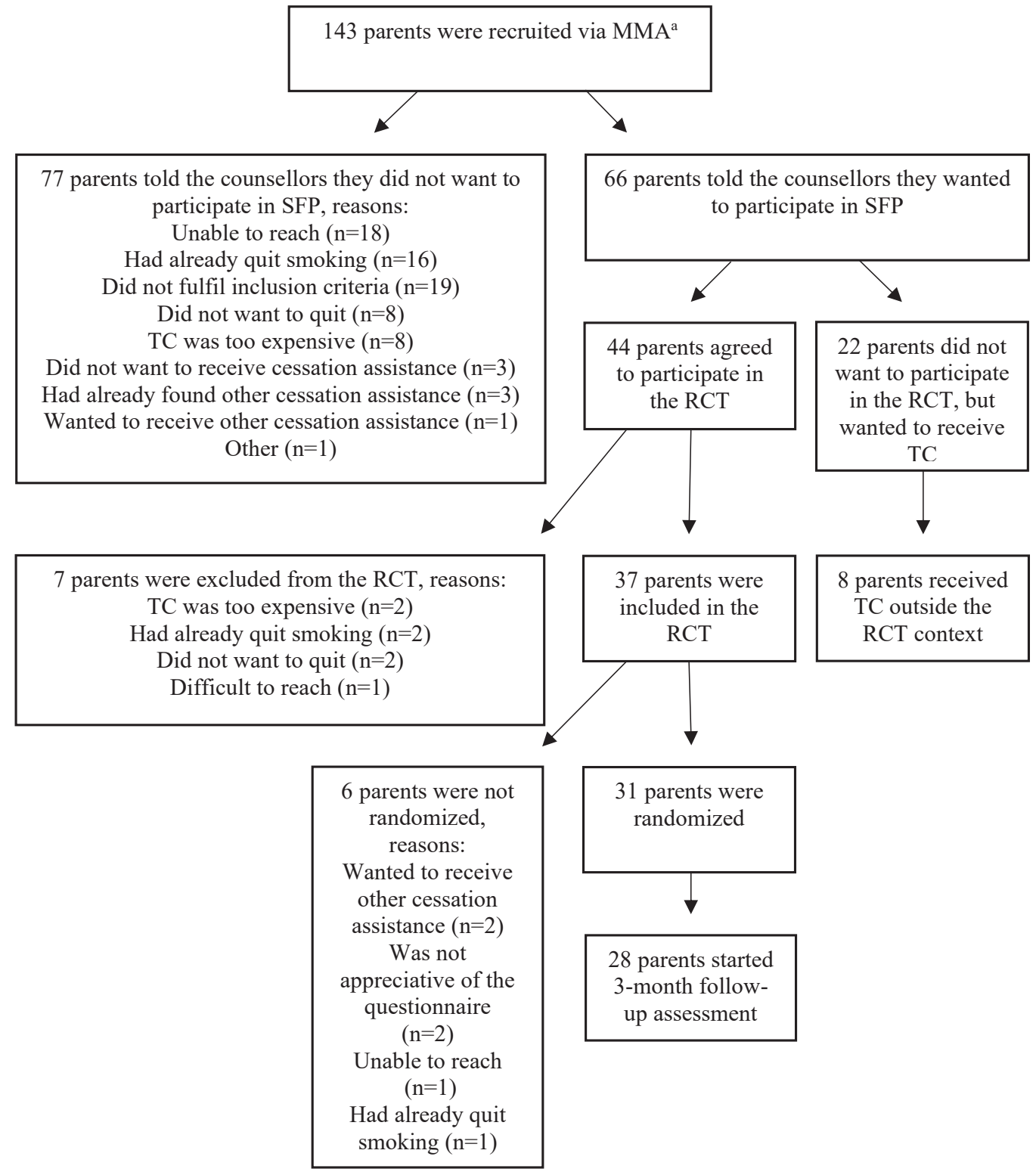

MMA: mass media approach. RCT: randomized controlled trial. SFP: smoke-free parents. TC: telephone counselling. a For nine parents it was unknown by which recruitment approach they were recruited. Therefore, the sum of parents who were recruited via the mass media approach and healthcare approach is not equal to the total number of parents that were recruited $(n=402)$. 
Figure 3. Flowchart HCA (The Netherlands, 2016-2018)

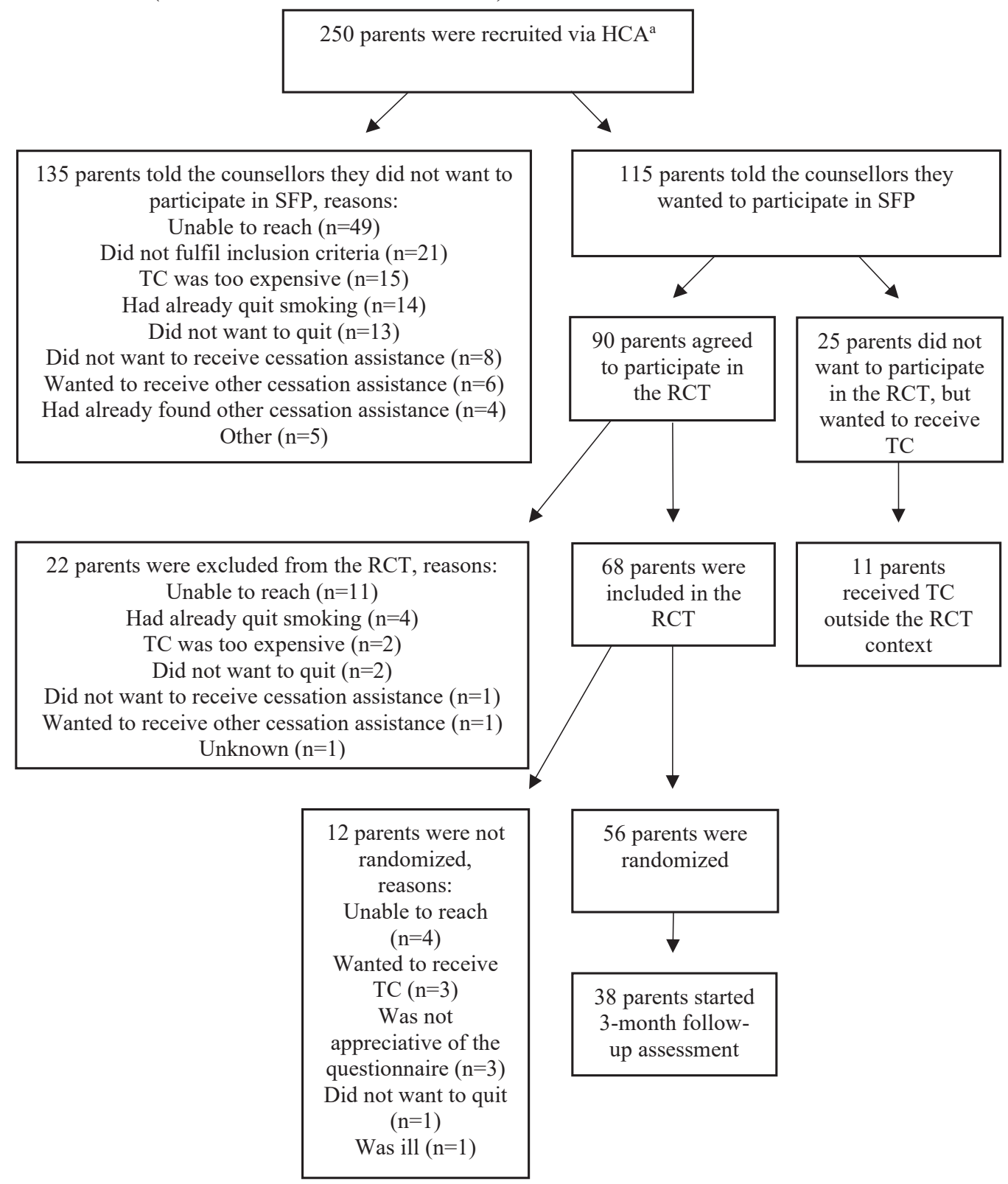

HCA: healthcare approach. MMA: mass media approach. SFP: smoke-free parents. TC: telephone counselling. a For nine parents it was unknown by which recruitment approach they were recruited. Therefore, the sum of parents who were recruited via the MMA and HCA is not equal to the total number of parents that were recruited ( $n=402$ ).

Regarding recruitment costs (Table 1), the CPP was substantially higher for the mass media approach ( $€$ 205.72) than for the healthcare approach (€99.62). More specifically, the recruitment costs for primary schools were $€ 4427.90$ (CPP: $€ 340.61$ ). For online mass media, recruitment costs were $€ 3595.37$ (CPP: $€ 138.28)$.

\section{Parents' barriers to participation in SFP}

As illustrated in Table 2, 'unable to reach' was most often found as reason for not participating in SFP $(32.7 \%)$. In addition, parents often mentioned that they had already quit smoking $(15.0 \%)$ or that SFP was too expensive $(10.5 \%)$. Concerning the mass media approach (Figure 2 and Table 2), the most common reasons were 'unable to reach' $(23.4 \%)$ and 'had already quit smoking' (20.8\%). Parents who were recruited via the healthcare approach (Figure 3 and Table 2) were most often unable to reach by the smoking cessation counsellors $(36.3 \%)$ or did not 
Table 1. Recruitment costs (in Euros) and CPP ${ }^{\text {a }}$ for the mass media approach and HCA, the Netherlands, 2016-2018 ( $\mathrm{N}=106)$

\begin{tabular}{lcc} 
Recruitment costs & $\begin{array}{c}\text { MMA } \\
(n=39) *\end{array}$ & $\begin{array}{c}\text { HCA } \\
(n=67) *\end{array}$ \\
\hline Dissemination of letters to primary schools & 372.58 & NA \\
Website primary schools & 4055.32 & NA \\
Social media & 3389.67 & NA \\
National smoking cessation website & 205.70 & NA \\
Development of materials & NA & 4286.43 \\
Dissemination of materials & NA & 1045.57 \\
Promotion costs conferences & NA & 1242.88 \\
Social media & NA & 99.71 \\
Total costs & 8023.27 & 6674.59 \\
CPP & 205.72 & 99.62
\end{tabular}

CPP: cost per participant. HCA: healthcare approach. MMA: mass media approach. NA: not applicable. a The CPP is based on the total recruitment costs divided by the number of parents who participated in SFP (i.e. sum of parents who were randomized in the RCT and parents who received telephone counselling outside the RCT). * Number of parents.

Table 2. Percentages of parents' barriers to participation in SFP overall and for the mass media approach and HCA, the Netherlands, 2016-2018 ( $\mathrm{N}=106)$

\begin{tabular}{|c|c|c|c|c|}
\hline Barriers & Overall & MMA & HCA & $\begin{array}{c}\text { Difference } \\
\text { between } \\
\text { approaches } \\
p\end{array}$ \\
\hline \multicolumn{5}{|l|}{ Reasons for declining } \\
\hline Had already quit smoking & 15.0 & 20.8 & 10.4 & $0.04^{*}$ \\
\hline $\mathrm{TC}$ was too expensive & 10.5 & 10.4 & 11.1 & 0.87 \\
\hline Did not want to quit & 9.5 & 10.4 & 9.6 & 0.86 \\
\hline $\begin{array}{l}\text { Did not want to receive } \\
\text { cessation assistance }\end{array}$ & 5.0 & 3.9 & 5.9 & 0.52 \\
\hline $\begin{array}{l}\text { Had already found other } \\
\text { cessation assistance }\end{array}$ & 3.2 & 3.9 & 3.0 & 0.71 \\
\hline $\begin{array}{l}\text { Wanted to receive other } \\
\text { cessation assistance }\end{array}$ & 3.2 & 1.3 & 4.4 & 0.22 \\
\hline Other & 2.7 & 1.3 & 3.7 & 0.31 \\
\hline \multicolumn{5}{|l|}{$\begin{array}{l}\text { Other reasons for not } \\
\text { participating after referral }\end{array}$} \\
\hline Unable to reach ${ }^{\mathrm{a}}$ & 32.7 & 23.4 & 36.3 & 0.05 \\
\hline $\begin{array}{l}\text { Did not fulfil inclusion } \\
\text { criteria }^{\text {b }}\end{array}$ & 18.2 & 24.7 & 15.6 & 0.15 \\
\hline \multicolumn{5}{|c|}{$\begin{array}{l}\text { HCA: healthcare approach. MMA: mass media approach. TC: telephone counselling. } \\
\text { a Unable to reach was identified by the research team when the smoking cessation } \\
\text { counsellors were either unable to reach parents at all or unable to reach parents } \\
\text { after they had been able to reach parents once. b Examples of the inclusion criteria } \\
\text { for the RCT were: } 1 \text { ) being at least a weekly smoker; } 2 \text { ) being a parent/caretaker of a } \\
\text { child aged } 0-18 \text { years; and 3) having the intention to quit smoking currently or in the } \\
\text { future }{ }^{18}{ }^{*} \text { Statistically significant, } p<0.05 \text {. }\end{array}$} \\
\hline
\end{tabular}

fulfil the inclusion criteria (15.6\%). The reason 'had already quit smoking' was significantly more often mentioned by parents recruited via the mass media approach versus the healthcare approach.

\section{Characteristics of parents who participated in SFP versus those who did not}

Parents who participated in SFP were significantly older than parents who did not [mean age 39.61 years $(\mathrm{SD}=7.28)$ vs 36.97 years $(\mathrm{SD}=7.40)$; $\mathrm{t}(187)=-2.636$, $\mathrm{p}=0.009]$. No significant differences were found for gender $\left(X^{2}=0.000, p=0.985\right)$, educational level $\left(\chi^{2}=0.481, p=0.786\right)$, or average number of cigarettes smoked daily $[\mathrm{t}(228)=0.068, \mathrm{p}=0.946]$.

\section{DISCUSSION}

This study examined program uptake and costs of mass media approach and healthcare approach for the proactive parent-tailored telephone smoking cessation counselling program $\mathrm{SFP}^{6,18}$. A key finding was that only $26.4 \%$ of the parents contacted via the recruitment approaches participated in SFP. Both approaches were equally useful for recruiting parents for SFP, as there were no statistically significant differences in program uptake. However, CPP was substantially lower for the healthcare approach versus mass media approach, although the CPP of both approaches was lower than found in other research ${ }^{22}$.

In comparison with other studies assessing program uptake of smokers who were recruited via child healthcare settings and referred to a quitline, the rates found in this study $(26.8 \%)$ were in the mid-range $\left(15 \%{ }^{9}, 29 \%^{23}\right.$, and $84 \%^{24}$, respectively). The high drop-out of parents after referral was caused by several barriers that prevented parents from participating in SFP. For example, the results show that the reason 'had already quit smoking' was significantly more identified in the mass media approach compared to the healthcare approach. When looking into the four different recruitment channels, the results suggest that the percentage of parents reporting that they had already quit smoking was higher in the online mass media channel (25.4\%) compared to other channels (e.g. medical healthcare professionals: $10.4 \%$; primary schools: $0 \%)$. However, caution is needed when interpreting these results, since the number of parents that were recruited via each recruitment channel substantially 
differed (range: 24-224).

Three main barriers were found that prevented parents from participating in SFP. First, $10.5 \%$ of the parents cited the high costs of SFP as a reason for declining when parents discussed the costs of SFP with the smoking cessation counsellors during the informal phone call. During the study, SFP cost between $€ 302.50(2016 / 2017)$ and $€ 363$ (2018). When this study was conducted, most health insurance agencies reimbursed the costs for smoking cessation support once a year, but the amount of reimbursement varied by health insurance type $\mathrm{e}^{20}$. Evidence shows that while partial reimbursement versus no reimbursement did not significantly increase the use of smoking cessation interventions, full reimbursement of these interventions compared to no reimbursement did increase the use of interventions, the number of quit attempts, and the abstinence rates at six months or longer ${ }^{25}$. Thus, full reimbursement of smoking cessation treatment seems to be important to increase reach and impact.

A second reason that parents mentioned for declining to participate in SFP concerned lack of motivation to quit $(9.5 \%)$, which is in line with other research ${ }^{26}$. Recruiting parents for smoking cessation interventions in the context of their children's health could be a strength, because there may be a teachable moment for motivating a quit attempt $\mathrm{t}^{8-10}$. However, recruiting parents for smoking cessation treatment could also be more challenging, because they are less likely to experience serious smokingrelated health consequences compared to smokers of older ages ${ }^{27}$, and, therefore, they may be less likely to be motivated to quit smoking and receive assistance. One potential way to increase parents' motivation may be to focus on the role conflict between being a parent and a smoker. One study found that parents who experienced this conflict were more likely to plan to quit smoking in the future ${ }^{28}$.

Another important reason for non-participation in SFP was that smoking cessation counsellors were unable to reach $32.7 \%$ of the parents after they had agreed to be called about SFP. Difficulty reaching smokers after they have been referred to a quitline is a common barrier ${ }^{29}$. Although our smoking cessation counsellors attempted to connect with parents by sending text messages and e-mails in addition to their call attempts, future research might examine the effectiveness of utilizing and personalizing these lower cost strategies and employing different framing strategies (e.g. loss vs gain). Future research could explore effective ways to reach difficultto-reach parents and motivate them to engage in smoking cessation interventions.

\section{Limitations}

Several limitations of this study should be acknowledged. First, due to the study design we were unable to examine the reach of SFP (i.e. the total number of parents that was actually reached with SFP). To gain more insight into the potential reach of SFP, further research is warranted. Second, the examination of the costs of the recruitment approaches did not include any personnel costs (e.g. costs of the research team's time investment). The research team's time investment could have influenced the results of the present study. However, as a research team we aimed to influence the recruitment of parents as little as possible, because we wanted to examine the recruitment under real-world conditions. Related to this, the length of time it took healthcare professionals to refer parents to SFP was also not examined. However, we expect this time cost to be minimal, since healthcare professionals reported that the referral tool was convenient and time-saving.

\section{Implications for practice and directions for future research}

Based on the results of this study, it could be concluded that the healthcare approach is a more successful recruitment approach than the mass media approach, since the recruitment costs were substantially lower and there was no significant difference in the rates of program uptake. However, the recruitment approaches could reach different subgroups of parents. Our data showed that, compared to parents who were recruited via the mass media approach, parents recruited via the healthcare approach were younger, less educated, and more likely to have a child with chronic respiratory illness ${ }^{18}$. Thus, by using both recruitment approaches, it is likely that a more diverse group of smoking parents can be reached for SFP.

Although the rates of program uptake of SFP fall within the wide range of previous studies, future research could examine how the program uptake could be improved to enhance the impact 
of SFP, such as by altering some of the recruitment strategies. For example, distributing invitation letters to parents via their children's primary schools might be less successful than giving short presentations on SFP during parent sessions at schools. In addition, program uptake could be improved by overcoming the barriers that parents reported in this study. For example, health insurance agencies and governments could explore ways to provide full reimbursement of SFP.

\section{CONCLUSIONS}

This study shows that the mass media approach and healthcare approach can be used to recruit parents for SFP. In addition, multiple barriers were identified that prevented parents from participating in SFP, including the costs of SFP and parents' lack of motivation to quit smoking. To increase the number of parents that start SFP, it is important to find solutions to overcome these barriers.

\section{REFERENCES}

1. Öberg M, Jaakkola MS, Woodward A, Peruga A, PrüssUstün A. Worldwide burden of disease from exposure to second-hand smoke: a retrospective analysis of data from 192 countries. Lancet. 201;377(9760):139-146. doi:10.1016/S0140-6736(10)61388-8

2. DiFranza JR, Aligne CA, Weitzman M. Prenatal and postnatal environmental tobacco smoke exposure and children's health. Pediatrics. 2004;113(4 Suppl):1007-1015. Accessed January 22, 2021. https:// pediatrics.aappublications.org/content/pediatrics/113/ Supplement_3/1007.full-text.pdf

3. U.S. Department of Health and Human Services. The Health Consequences of Involuntary Exposure to Tobacco Smoke: A Report of the Surgeon General. Atlanta, GA: U.S. Department of Health and Human Services, Centers for Disease Control and Prevention, Coordinating Center for Health Promotion, National Center for Chronic Disease Prevention and Health Promotion, Office on Smoking and Health; 2006. Accessed January 22, 2021. https://www.ncbi.nlm.nih.gov/books/NBK44324/pdf/ Bookshelf_NBK44324.pdf

4. Matt GE, Quintana PJ, Destaillats H, et al. Thirdhand tobacco smoke: emerging evidence and arguments for a multidisciplinary research agenda. Environ Health Perspect. 2011;119(9):1218-1226. doi:10.1289/ehp.1103500

5. Hymowitz N, Schwab J, Haddock Ck, Pyle S, Moore G, Meshberg S. The pediatric resident training on tobacco project: baseline findings from the Parent/Guardian Tobacco Survey. Prev Med. 2005;41(1):334-341. doi:10.1016/j.ypmed.2004.11.019
6. Schuck K, Bricker JB, Otten R, Kleinjan M, Brandon TH, Engels RC. Effectiveness of proactive quitline counselling for smoking parents recruited through primary schools: results of a randomized controlled trial. Addiction. 2014;109(5):830-41. doi:10.1111/add.12485

7. McClure JB, Greene SM, Wiese C, Johnson KE, Alexander $\mathrm{G}$, Strecher V. Interest in an online smoking cessation program and effective recruitment strategies: results from Project Quit. J Med Internet Res. 2006;8(3):e14. doi:10.2196/jmir.8.3.e14

8. Winickoff JP, Hillis VJ, Palfrey JS, Perrin JM, Rigotti NA. A smoking cessation intervention for parents of children who are hospitalized for respiratory illness: the stop tobacco outreach program. Pediatrics. 2003;111(1):140145. doi:10.1542/peds.111.1.140

9. Mahabee-Gittens EM, Gordon JS, Krugh ME, Henry B, Leonard AC. A smoking cessation intervention plus proactive quitline referral in the pediatric emergency department: a pilot study. Nicotine Tob Res. 2008;10(12):1745-1751. doi:10.1080/14622200802443494

10. Curry SJ, Ludman EJ, Graham E, Stout J, Grothaus L, Lozano P. Pediatric-based smoking cessation intervention for low-income women: a randomized trial. Arch Pediatr Adolesc Med. 2003;157(3):295-302. doi:10.1001/archpedi.157.3.295

11. Winickoff JP, Tanski SE, McMillen RC, Hipple BJ, Friebely J, Healey EA. A national survey of the acceptability of quitlines to help parents quit smoking. Pediatrics. 2006;117(4):e695-700. doi:10.1542/peds.2005-1946

12. Drehmer JE, Hipple B, Nabi-Burza E, Ossip DJ, Chang Y, Rigotti NA, Winickoff JP. Proactive enrollment of parents to tobacco quitlines in pediatric practices is associated with greater quitline use: a cross-sectional study. BMC Public Health. 2016;16:520. doi:10.1186/s12889-016-3147-1

13. Reid JL, Hammond D, Boudreau C, Fong GT, Siahpush M. Socioeconomic disparities in quit intentions, quit attempts, and smoking abstinence among smokers in four western countries: findings from the International Tobacco Control Four Country Survey. Nicotine Tob Res. 2010;12(Suppl 1):S20-33. doi:10.1093/ntr/ntq051

14. Hyland A, Borland R, Li Q, et al. Individual-level predictors of cessation behaviours among participants in the International Tobacco Control (ITC) Four Country Survey. Tob Control. 2006;15(Suppl 3):iii83-94. doi:10.1136/tc.2005.013516

15. Bernet AC, Willens DE, Bauer MS. Effectivenessimplementation hybrid designs: implications for quality improvement science. Implement Sci. 2013;8(Suppl 1):S2. doi:10.1186/1748-5908-8-S1-S2

16. Curran GM, Bauer M, Mittman B, Pyne JM, Stetler C. Effectiveness-implementation hybrid designs: combining elements of clinical effectiveness and implementation research to enhance public health impact. Med Care. 2012;50(3):217226. doi:10.1097/MLR.0b013e3182408812

17. Scheffers-van Schayck T, Otten R, Engels R, Kleinjan M. Evaluation and Implementation of a Proactive Telephone 
Smoking Cessation Counseling for Parents: A Study Protocol of an Effectiveness Implementation Hybrid Design. Int J Environ Res Public Health. 2018;15(1):97. doi:10.3390/ijerph15010097

18. Scheffers-van Schayck T, Otten R, Engels RCME, Kleinjan M. Proactive Telephone Smoking Cessation Counseling Tailored to Parents: Results of a Randomized Controlled Effectiveness Trial. Int J Environ Res Public Health. 2019;16(15):2730. doi: 10.3390/ijerph16152730

19. Ouders geven consultatiebureau gemiddeld een ruime 7. Parents give child health centres a 7 out of 10 . Centraal Bureau voor de Statistiek. October 30, 2014. Accessed October 14, 2019. https://www.cbs.nl/nl-nl/ nieuws/2014/44/ouders-geven-consultatiebureaugemiddeld-een-ruime-7

20. Trimbos Institute. Allowance for smoking cessation. Vergoeding voor stoppen met roken. Rokeninfo. Accessed May 24, 2019. https://www.rokeninfo.nl/publiek/ vergoedingen

21. Standaard Onderwijsindeling 2016. Centraal Bureau voor de Statistiek. Accessed January 22, 2021. https://www. cbs.nl/nl-nl/onze-diensten/methoden/classificaties/ onderwijs-en-beroepen/standaard-onderwijsindeling-soi--/standaard-onderwijsindeling-2016

22. Lopez EN, Simmons VN, Quinn GP, Meade CD, Chirikos TN, Brandon TH. Clinical trials and tribulations: lessons learned from recruiting pregnant ex-smokers for relapse prevention. Nicotine Tob Res. 2008;10(1):87-96. doi:10.1080/14622200701704962

23. Sisterhen LL, Sheffer CE, Bursac Z, Fischer EP. Rates of enrollment in smoking cessation services following fax referrals from a children's hospital. Acad Pediatr. 2010;10(3):200-204. doi:10.1016/j.acap.2010.03.001

24. Winickoff JP, Healey EA, Regan S, Park ER, Cole C, Friebely J, Rigotti NA. Using the postpartum hospital stay to address mothers' and fathers' smoking: the NEWS study. Pediatrics. 2010;125(3):518-525. doi:10.1542/peds.2009-0356

25. van den Brand FA, Nagelhout GE, Reda AA, et al. Healthcare financing systems for increasing the use of tobacco dependence treatment. Cochrane Database Syst Rev. 2017;9(9):CD004305. doi:10.1002/14651858.CD004305.pub5

26. Burns EK, Deaton EA, Levinson AH. Rates and reasons: disparities in low intentions to use a state smoking cessation quitline. Am J Health Promot. 2011;25(5 Suppl):S59-65. doi:10.4278/ajhp.100611-QUAN-183

27. Jha P, Peto R. Global effects of smoking, of quitting, and of taxing tobacco. N Engl J Med. 2014;370(1):60-68. doi:10.1056/NEJMra1308383

28. Friebely J, Rigotti NA, Chang Y, et al. Parent smoker role conflict and planning to quit smoking: a crosssectional study. BMC Public Health. 2013;13:164. doi:10.1186/1471-2458-13-164

29. Willett JG, Hood NE, Burns EK, et al. Clinical faxed referrals to a tobacco quitline: reach, enrollment, and participant characteristics. Am J Prev Med. 2009;36(4):337-340. doi:10.1016/j.amepre.2008.12.004

\section{CONFLICTS OF INTEREST}

The authors have each completed and submitted an ICMJE form for disclosure of potential conflicts of interest. The authors declare that they have no competing interests, financial or otherwise, related to the current work. T. Scheffers-van Schayck reports grants from Dutch Cancer Society, during the conduct of the study. The rest of the authors have nothing to disclose.

\section{FUNDING}

This work was supported by the Dutch Cancer Society (Grant number: 2015-7944). The funding body had no role in the design of the study and collection, analysis, and interpretation of data, and in writing the manuscript.

\section{ETHICAL APPROVAL AND INFORMED CONSENT}

This study was registered in the Netherlands Trial Register (NTR6092) and approved by the ethics committee of the Trimbos Institute (201607_521606). Consent to participate in the RCT was obtained by a completed registration form.

\section{PROVENANCE AND PEER REVIEW}

Not commissioned; externally peer reviewed. 